\title{
HUBUNGAN ANTARA PENGETAHUAN PENCEMARAN LINGKUNGAN TERHADAP PARTISIPASI IBU RUMAH TANGGA DALAM MELINDUNGI LINGKUNGAN
}

\author{
Saifullah1, Sriaryaningsyih ${ }^{2}$ \\ 1,2 Program Studi Pendidikan Matematika, STKIP Bima. Jalan Piere Tendean Kel. Mande Tel. Fax (0374) \\ 42801, Bima 84191, Indonesia \\ (Email: faithfaqih@gmail.com)
}

\begin{abstract}
Abstrak
Penelitian adalah survey dengan pendekatan korelasional. Perolehan data primer dilapangan menggunakan kuesioner yang disusun berdasarkan indikator-indikator yang ada dalam masing-masing variabel penelitian. Tujuan penelitian ini adalah untuk mengetahui hubungan antara dua variabel independen dengan variabel dependen. Penelitian ini menggunakan metode survei, dengan 101 responden. Pengambilan sampel dilakukan dengan proportionate cluster / area random sampling. Lokasi Penelitian ini dilakukan di Bantaran Sungai Padolo Kelurahan Dara kecamatan Rasana'e Barat Kota Bima. Analisis data menggunakan korelasi dan regresi sederhana. Hasil penelitian menunjukan bahwa ada hubungan positif yang signifikan antara pengetahuan tentang pencemaran lingkungan terhadap partisipasi ibu rumah tangga dalam perlindungan Lingkungan.
\end{abstract}

Kata kunci: Pengetahuan Pencemaran Lingkungan, Partisipasi Melindungi Lingkungan

\section{PENDAHULUAN}

Alam merupakan anugerah Allah SWT yang harus dilindungi dari kerusakan. Sebab baik buruknya kualitas hidup manusia tergantng sungguh dari pada kondisi lingkungan itu sendiri. tak jarang didalam kondisi lingkungan yang rusak maka akan menimbulkan ancaman tersendiri bagi masyarakat yang hidup disekitarnya.

Selama ini perempuan kurang diikutsertakan dalam upaya perlindungan lingkungan hidup baik itu dalam akses, partisipasi, kontrol dan manfaat. Padahal, pola pikir, budaya dan kedekatan secara fisik dan emosional antara perempuan dengan lingkungandapat diarahkan untuk upaya tersebut.

Partisipasi seperti yang didefinisikan oleh
Davis (1985) adalah keterlibatan mental dan emosional seseorang individu dalam situasi kelompok tertentu yang mendorongnya untuk mendukung atau menunjang tercapainya tujuantujuan kelompok serta ikut bertanggung jawab terhadapnya.

Sementara itu, United Nations (2011) merumuskan definisi perlindungan lingkungan (environmental protection) sebagai berikut:"“ Environmental protection groups together all actions and activities that are aimed at the prevention, reduction and elimination of pollution as well as any other degradation of the environment. This includes measures taken in order to restore the environment after it has been degraded due to the pressures from human activities.

Hal ini berarti, perlindungan lingkungan merupakan seluruh aktifitas yang bertujuan 
untuk mencegah, mengurangi dan mengeliminir pencemaran dan degradasi lingkungan. Termasuk aktifitas memperbaiki lingkungan yang rusak akibat aktifitas manusia. Document UN Women November (2011) disebutkan peran serta yang sama dan wewenang dari perempuan merupakan kesatuan integral untuk mencapai tiga pilar pembangunan berkelanjutan, yakni dalam bidang sosial, ekonomi dan lingkungan. Jumlah perempuan yang lebih dari setengah populasi dunia, memainkan peran penting dalam perlindungan lingkungan baik skala rumah tangga maupun skala masyarakat.

Partisipasi ibu rumah tangga dalam melindungi lingkungan dapat ditingkatkan dengan memberikan pengetahuan lingkungan hidup seperti tentang pencemaran lingkungan, dan juga dengan membangun kecerdasan terkait lingkungan hidup. Dalam Tbilisi Document (1977) dirumuskan, pendidikan lingkungan hidup (environmental education) bertujuan untuk memberikan kepada masyarakat pengetahuan, keterampilan dan sikap yang menumbuhkan kepedulian, komitmen untuk melindungi, memperbaiki serta memanfaatkan lingkungan hidup secara bijaksana, menciptakan pola perilaku yang bersahabat dengan lingkungan, mengembangkan etika lingkungan hidup dan untuk memperbaiki kualitas hidup.

Penelitian tentang hubungan antara pengetahuan pencemaran lingkungan terhadap partisipasi ibu rumah tangga dalam melindungi lingkungan sangat penting untuk dilakukan.
Hasil dari penelitian, diharapkan dapat menjadi dasar bagi upaya intensif perlindungan lingkungan dan dapat memberikan masukan berharga kepada seluruh pihak terkait upaya perlindungan lingkungan hidup.

\section{METODE PENELITIAN}

Metode penelitian adalah survey dengan pendekatan korelasional. Perolehan data primer dilapangan menggunakan kuesioner yang disusun berdasarkan indikator-indikator yang ada dalam masing-masing variabel penelitian, yaitu pengetahuan pencemaran lingkungan (X1), dan partisipasi ibu rumah tangga dalam melindungi lingkungan $(\mathrm{Y})$.

Populasi dalam penelitian ini adalah ibu rumah tangga yang bertempat tinggal di bantaran Sungai Padolo Kelurahan dara Kecamatan Rasana'e Barat Kota Bima yang berpendidikan minimal SD. Teknik sampling secara Proportionate Cluster/Area Random Sampling, dengan jumlah sampel 101 yang ditentukan dengan formula Slovin sebagai berikut:

$$
n=\frac{N}{1+N(e)^{2}}
$$

Keterangan :

$\mathrm{n}=$ ukuran sampel

$\mathrm{N}=$ ukuran populasi

$\mathrm{e}=$ taraf signifikansi $(5 \%)$

Analisa dilakukan dua tahap, dengan statistika deskriptif dan dengan statistika inferensial untuk menguji hipotesis dengan teknik korelasi dan regresi. Uji signifikansi 
menggunakan analisis korelasi Product Moment

Pearson. Sebelumnya dilakukan pengujian prasyarat analisis, meliputi uji normalitas metode Lillyefors dan uji homogenitas metode Bartlet's.

Pengujian hipotesis dilakukan dengan teknik uji signifikasi regresi dan korelasi sederhana, serta uji signifikasi regresi.

\section{HASIL DAN PEMBAHASAN}

Hasil uji hipotesis Diperoleh persamaan regresi : $\hat{\mathrm{Y}} 1=114,004+0,788 \mathrm{X} 1 . \mathrm{Uji}$ Linearitas menunjukkan bahwa regresi bersifat linear (nilai (Sig.) 0,218> 0,05). Hasil uji signifikansi regresi menunjukan nilai Sig. 0,002 $<0,05(\alpha=0,05)$ yang menunjukkan signifikan.

Diperoleh koefisien korelasi (ry1) sebesar 0,302 dan nilai uji signifikan (Sig.) adalah 0,002 $<0,05(\alpha=0,05)$ yang menunjukan signifikan. Nilai koefisien determinan (r2y1) sebesar 0,091, artinya $9,1 \%$ partisipasi ibu rumah tangga dalam melindungi lingkungan dapat ditentukan oleh pengetahuan pencemaran lingkungan.

Hasil penelitian menunjukkan terdapat korelasi yang signifikan antara pengetahuan pencemaran lingkungan dengan partisipasi ibu rumah tangga dalam melindungi lingkungan

Pengetahuan seseorang akan mendasari perilaku dan keterlibatannya dalam suatu aktifitas. Seseorang dengan pengetahuan pencemaran lingkungan yang dimilikinya akan berperan aktif dalam upaya perlindungan lingkungan
Hal ini sesuai dengan pendapat Suriasumantri (2006) bahwa pengetahuan manusia muncul dari kepercayaan yang benar, yang mengandung bukti dari suatu fakta, memunculkan persepsi, yang akan mendasari praktek. Hal ini senada juga dengan pendapat bahwa pengetahuan mempengaruhi kreatifitas, dimana daya kreatif tumbuh dari dalam diri seseorang dan merupakan pengalaman yang mendalam, memiliki proses dan produk serta tahap, tingkat dan urutan tertentu. Hal ini juga sesuai dengan taksonomi Bloom (1981) tentang domain kognitif yang mencakup kemampuan intelektual mengenai lingkungan diantaranya kemampuan mempergunakan halhal yang telah dipelajari untuk menghadapi situasi-situasi baru yang nyata.

Dari pembahasan teori diatas, adalah logis jika pengetahuan pencemaran lingkungan yang dimiliki oleh ibu rumah tangga akan berpengaruh positif dan signifikan dengan partisipasi ibu rumah tangga dalam melindungi lingkungan. Partisipasi dalam melindungi lingkungan khususnya pada ibu rumah tangga di sekitar Sungai padolo kelurahan dara, diprediksikan tergantung kepada berbagai faktor selain variabel diatas. Partisipasi ditentukan oleh kelembagaan, kebijakan, dan stakeholders. Terkait dengan partisipasi dalam melindungi lingkungan, Solomon (2010) menyebutkan bahwa hal ini ditentukan oleh beberapa komponen, yaitu etika, pendidikan dan 
Hubungan Antara Pengetahuan Pencemaran Lingkungan Terhadap Partisipasi Ibu

Rumah Tangga Dalam Melindungi Lingkungan

ISSN:2599-1337 (online)

ISSN:2089-3205 (cetak)

legislasi lingkungan. Dengan demikian,

penelitian mengenai partisipasi ini dengan

menggunakan variabel-varibel yang lain sangat menarik dan penting untuk dilakukan.

\section{KESIMPULAN}

Terdapat hubungan positif yang signifikan antara pengetahuan pencemaran lingkungan dengan partisipasi ibu rumah tangga dalam melindungi lingkungan. dengan koefisien korelasi (ry1) sebesar 0,302 dan nilai uji signifikan (Sig.) adalah $0,002<0,05$ $(\alpha=0,05)$ yang menunjukan signifikan. Nilai koefisien determinan (r2y1) sebesar 0,091, artinya $9,1 \%$ partisipasi ibu rumah tangga dalam melindungi lingkungan dapat ditentukan oleh pengetahuan pencemaran lingkungan.

\section{DAFTAR PUSTAKA}

Amstrong, Thomas, (2002). Sekolah Para Juara. Bandung : Penerbit Kaifa.

Bloom, B.S. (Ed.), Engelhart, M.D., Furst, E.J., Hill, W.H., \& Krathwohl, D.R, (1981). Taxonomy of Educational Objectives : Handbook I Cognitive Domain. New York: Longman Inc.

Conny R.Semiawan, I. Made Putrawan, I. Setiawan, Dimensi Kreatif Dalam Filsafat Ilmu (Bandung : Remaja Rosdakarya, 1998

Jujun S. Suriasumantri, (2006). Ilmu dalam Persfektif Jakarta : Yayasan Obor Indonesia.

Solomon, Uchechukwu, (2010 ). "A Detailed
Look at the Three Disciplines, Environmental Ethics, Law and Education to Determine which Plays the Most Critical Role in Environmental Enhancement and Protection", Journal Environment, Development and Sustainability, Vol.12, No.6.

Tri Marhaeni Pudji Astuti, (2012). "Ekofeminisme dan Peran Perempuan Dalam Lingkungan", Indonesian Journal of Conservation, Vol.1, No.1.

Umi Hidayati, Sujanti, Hery Wahyuningtyastuti dan Pantyo Nugroho Probokusumo, (2005). Pengkajian Partisipasi Masyarakat dalam Penanganan Masalah Sosial Perempuan Korban Tindak Kekerasan. Yogyakarta : Departemen Sosial RI, 2005.

UN WOMEN, (2011). "The Centrality of Gender Equality and the Empowerment of Women for Sustainable Development", Contribution to the Outcome Document UN Women.

United Nations, (2011). Draft Classification of Environmental Activities and Expenditures (draft CEA 2011). New York: Department of Economic and Social Affairs Statistic Division, Expert Group Meeting on International Economicand Social Classifications.

United States Environmental Protection, (2000) Community Based Environmental Protection : A Resource Book for Protecting Ecosystem and Communities.Washingthon, D.C : U.S. EPA. 